Meta

Journal des traducteurs

Translators' Journal

\title{
Problems of Mining Terminology in India
}

\section{R. K. Singh}

Volume 31, numéro 2, juin 1986

URI : https://id.erudit.org/iderudit/004163ar

DOI : https://doi.org/10.7202/004163ar

Aller au sommaire du numéro

\section{Éditeur(s)}

Les Presses de l'Université de Montréal

\section{ISSN}

0026-0452 (imprimé)

1492-1421 (numérique)

Découvrir la revue

Citer cet article

Singh, R. K. (1986). Problems of Mining Terminology in India. Meta, 31(2), 173-178. https://doi.org/10.7202/004163ar

\section{Résumé de l'article}

In 1961 the Government of India appointed a Standing Commission for Scientific and Technical Terminology to formulate principles for evolution of terminology and preparation of standard textbooks in Hindi and other Indian Languages. The Commission published several glossaries of Engineering terminology, but none of mining engineering. From 1943 to 1954, Professor Raghu Vira, the noted Indian linguist, also published quite a few special dictionaries, and for the first time collected and compiled some mining terms in his Comprehensive English-Hindi Dictionary (1981). Though these indicate a first positive move toward collecting, processing and disseminating specialised vocabularies, their authors' principles and methods of developing terminologies vary. For want of a standard terminology of mining in Hindi and a lack of understanding of terminological concepts and their

interrelationships, no textbook of mining could be written in or translated into Indian languages. It is also realised that translation of mining literature should be done by mining engineer translators who understand the systems of concepts, systems of terms and principles of translation. For a wider dissemination of scientific knowledge and technical skills, development of terminologies in Indian languages on internationally accepted sound terminological principles is necessary, even though presently subject specialists communicate in English. With the present government formulating programmes to use on a large scale the new communication technology in our school system, teaching of terminology within the framework of ESP syllabus at undergraduate level is also suggested.
Ce document est protégé par la loi sur le droit d'auteur. L'utilisation des services d'Érudit (y compris la reproduction) est assujettie à sa politique d'utilisation que vous pouvez consulter en ligne.

https://apropos.erudit.org/fr/usagers/politique-dutilisation/ 


\title{
ÉTUDES TERMINOLOGIQUES ET LINGUISTIQUES
}

\section{PROBLEMS OF MINING TERMINOLOGY IN INDIA}

\begin{abstract}
In 1961 the Government of India appointed a Standing Commission for Scientific and Technical Terminology to formulate principles for evolution of terminology and preparation of standard textbooks in Hindi and other Indian Languages. The Commission published several glossaries of Engineering terminology, but none of mining engineering.

From 1943 to 1954, Professor Raghu Vira, the noted Indian linguist, also published quite a few special dictionaries, and for the first time collected and compiled some mining terms in his Comprehensive English-Hindi Dictionary (1981).

Though these indicate a first positive move toward collecting, processing and disseminating specialised vocabularies, their authors' principles and methods of developing terminologies vary. For want of a standard terminology of mining in Hindi and a lack of understanding of terminological concepts and their interrelationships, no textbook of mining could be written in or translated into Indian languages. It is also realised that translation of mining literature should be done by mining engineer translators who understand the systems of concepts, systems of terms and principles of translation.

For a wider dissemination of scientific knowledge and technical skills, development of terminologies in Indian languages on internationally accepted sound terminological principles is necessary, even though presently subject specialists communicate in English.

With the present government formulating programmes to use on a large scale the new communication technology in our school system, teaching of terminology within the framework of ESP syllabus at undergraduate level is also suggested.
\end{abstract}

Recognising the serious communication problems which may result from the use of vague terms vis-a-vis the rapid advancement in various technical and professional streams, the Government of India appointed in 1961 a Standing Commission for Scientific and Technical Terminology, entrusting it, among other things, with two significant functions :

a) formulation of principles relating to coordination and evolution of scientific and technical terminology in Hindi and other regional languages; and

b) preparation of standard scientific textbooks using the new terminology evolved and approved by it, preparation of scientific and technical dictionaries and translation into Indian languages of scientific books in foreign languages ${ }^{1}$.

The Commission's contribution to the cause of Terminology in the last two decades relates to : appointment of expert advisory committees for different subjects to review and coordinate the terms prepared by the Ministry of Education, Central Hindi Directorate and other academic bodies; organisation of seminars to discuss the basic principles and linguistics of technical terminology ; and preparation and publication of bilingual English-Hindi glossaries of terms, covering, besides general sciences and mathematics, specialist subjects like electrical engineering, electronic and communica- 
tion engineering, soil mechanics, hydraulic engineering, railway engineering, irrigation engineering, mechanical engineering and civil engineering; but NOT mining engineering. The Commission also could not contribute to produce textbooks in Hindi or other Indian languages for use in technical universities, possibly, due not only to sociopolitical reasons but also to the problem both of internationalisation of terms and concepts and differences in various languages related to concept, meaning and linguistic symbol ${ }^{2}$.

Apart from the officially sponsored and prepared glossaries of scientific and technical terms, there have been a number of special dictionaries, prepared and published by Professor Raghu Vira, the noted Indian linguist, from 1943 to 1954. It is only he, who for the first time collected and compiled several mining terms in his voluminous Comprehensive English-Hindi Dictionary (1981). Though he does not seem to have attempted any special dictionary of mining terminology per se, he did issue a special dictionary Khanij Abhigyan dealing with terms of mineral science in 1953 prepared in collaboration, among others, with a professor of geology of Indian School of Mines, N.L. Sharma ${ }^{3}$. In 1947, he was also involved in preparation of over sixty undergraduate level textbooks in Hindi and Marathi on chemistry, mathematics, physics, botany and zoology. But, regrettably, no one wrote any textbook in Hindi or other Indian languages(s) on mining engineering.

Before I come to discuss other aspects of the terminology in mining, let me also point to the principles followed by the Standing Commission for evolution of scientific and technical terminology in Indian languages. In preparing the scientific terminology in Hindi, the Commission recommended : (i) adoption of international terms in their original/current English forms, and their transliteration in Hindi/other Indian languages according to their genius ; (ii) use of the symbols in the international form written in Roman script, but abbreviations in Nageri and standardised forms (e.g. 'cm' for centimetre, but the abbreviation in Nagari as से०मी०); (iii) translation of comptual terms ; (iv) selection of Hindi equivalents on the basis of simplicity, precision of meaning and easy intelligibility, avoiding obscurantism and purism; (v) selection of terms that are based on Sanskrit roots and are common to as many of the regional languages as possible ; (vi) use of indigenous terms which have come into vogue in Indian languages for certain scientific words of common use such as 'ter' (ताइ) for telegraph/ telegram, or 'paramanu (परमाणु) for stom; (vii) use of such loan words from English, Portuguese, French, etc., as have gained wide currency in Indian languages like engine, machine, metre, litre, torch, etc. ; (viii) transliteration of English terms be not so complex as to necessitate the introduction of new signs and symbols in the present Devanagari characters ; (ix) use of international terms (adopted) in Hindi) in the masculine gender; ( $\mathrm{x}$ ) use of hybrid forms in scientific terminologies, e.g. 'aayanikaran' ( ग्रायनीकरण ) for ionization, 'voltata' ( शेल्टतr) for voltage, 'madulit' (मादुलिता) for modulated, 'forjan' (फोर्जन) for forging, etc., keeping in view simplicity, utility and precision ; (xi) avoidance of the complex form of sandhi (combination) and in cases of compound words, use of hyphen in between the two terms for quicker understanding ; (xii) correct use of hal (the consonant sign ) in newly adopted terms, and (xiii) use of anuswar (the nasal sign used in writing Devanagari) in place of panchamwarna (the firth alphabet) 4 .

This codification of rules, howsoever insufficiant vis-a-vis the international terminological principles and methods, for communicating developments in the already sophisticated communication media today, was a positive move toward building a terminology system at national level.

Professor Raghu Vira in his dictionaries, however, follows a more classical and purist approach and stresses the use of Sanskrit-based terminology. His linguistic and philosophical insight into the dynamics of technical terms in Indian languages is firmly 
based on native grounds just as in his theoretical scheme he is guided by the need for lexical standardization at all-India level. Enunciating his general principles of terminology he postis : (i) one word conveys only one primary meaning ; (ii) words are significant in that they point to some salient features ; (iii) simple English words are translated by simple words and not by compounds or phrases ; (iv) a phrase cannot be used as a terms, and the length of simple uncompounded word is kept within bounds : two or three syllables form the norm ; (v) distinctive affixes of a particular branch of knowledge are normally to be translated by corresponding prefixes and suffixes, e.g. pari (पt) for pari-, anu (गत्रु) for sub-, dus (दुस) for dys-, eey (ईस) for -ate, etc.; when the English word is a significant compound and duly conveys its technical significance, the Indian word is similarly formed, i.e. translating precisely, word by word, abbreviation by abbreviation, number by number; (viii) if a term in English has a number of distinctive derivative, all of them are provided for, like law (vidhi), lawful (vidhisangat, Vidhiwat), legal (vaidh), etc. ; (viii) where needed a word is allowed one or more abridged forms, (ix) a word is considered with its grammatical derivatives (like nouns, verbs, adjectives) and semantically it is considered along with its synonyms and antonyms; $(x)$ in case of ideas and objects that have existed from ancient times, old names are assiduously hunted out from the vast range of Sanskrit, Pali and Prakrit literatures (to maintain historical continuity between the past and the present); (xi) for new ideas of science and technology new suffixes are devised ; and (xii) technical terms are considered a supplement to the general dictionary5.

Professor Raghu Vira also gives the Indian counterparts of Greek and Roman letters of the alphabet and uses the syllabic Devanagari letters as also the Brahmi script symbols of the time of Emperor Asoka for modern scientific symbols and abbreviations. His elaborate system of technical vocabulary standards, more scholarly and 'universalised' for Indian and neighboring countries, has no official sanction as such, nor has here been a wide acceptance and use of the terms recommended by him, but he has made a significant contribution to create a useful foundation for terminographic development in Indian Languages.

As for as Raghu Vira's insistence on use of purist, Sanskrit-derived terms is concerned, I should warn that Sanskrit (or other older Indian languages) may be serviceable for specific technical or higher purposes only if this language is taught well at high school / intermediate levels all over the country and teachers as well as researchers in technical subjects become 'terms' conscious. Given the present situation in the country, I doubt the Sanskritised terminology can be revived or used for communicating minutest precepts and concepts of foreign technical process developed over the past few decades.

However, there is an awareness of the terminological difficulties, like finding suitable terms to denote newly created or changed concepts that would allow clear communication in a subject field, or the systems of concept differing from language to language. As Professor Helmut Felber points out :

The number of roots in a particular language is minimal compared to the number of concepts to be denoted ; there are thousands of roots as opposed to millions of concepts. Therefore, most of the concepts have to be represented either by a combination of word elements or by transferred terms. This could lead to severe communication problems in the near future unless scientife methods are being applied to terminology work... Therefore, enormous efforts both on national and international level have to be undertaken to ensure proper communication in all subject fields and all languages, particularly in the language of those countries which function as carriers of scientific, technical and cultural progress ${ }^{6}$. 
The number of verbal roots in use (in Sanskrit) are, as Raghu Vira records, 520, though Panini, the greatest Sanskrit grammarian, recorded approximately 2000 . Of course, used with appropriate suffixes and prefixes, these roots may help to construct Indian equivalents for foreign terms, but, as Felber rightly points out, a few thousands of terms cannot communicate millions of concepts. For never ideas, new prefixes and suffixes may have to be devised, new words may have to be constructed. As I can see it, the escalating demand for technology and services in the field of Mining in India have accentuated the need for LSP practitioners to interact with the mining community and improve technical communications on sound terminological principles. There is the need to accept a scientific principle and methodology of terms formation at the national level. People will simply not use an unfamiliar terminology in their first language when a familiar, most commonly used and intelligible terminology is available, even if in English (or other second or third language).

Moreover, technical terms in Indian languages are not yet standardized. While Raghu Vira tries to give Hindi equivalents for each English term and concept, the writers of the Government of India glossaries retain the international, or commonly used terms in English, like barrel, drill, boiler, generator, bearings, carburetor, cell, clip, etc. and use hybrid formations. Both the dictionaries fail to record even such terms that cross across linguistic lines and are simple and intelligible, for instance, malkatta (मालकद्रा) for coal-cutter : the term is commonly used and understood by mining engineers and workers/miners between West Bengal, Bihar, Orissa and Madhya Pradesh, but while Raghu Vira gives a highly academic and Sanskritised terms angarkartak ( (प्रगारकर्तक), the Government of India glossary simply misses it. While terms like chaal ( चाल) for roof and chandani ( चांदनी) for roof which is likely to fall, are examples of a few Hindi terms unique to Indian mining, English terms like seam, haulage, cage, concrete, $t u b$, etc. are intelligible to every ordinary labourer, but Raghu Vira would prefer a pure Indian term.

The technical communication language between mining engineer/mining engineer is English or a regional language - English mixed (code-switching is frequent); even the semi-literate coal miners use English terms mixed with regional or local languages to communicate among themselves as also to their superiors. There is no standard terminology of mining in Indian languages as such ${ }^{7}$. With increased mechanisation of mines, mostly English terms are use for talking about various parts of machinaries, for example, blade, gear, brake, dumper, compressor, etc. People in mining industry have been accepting term from English without attempting to simplify or change it.

In general, the Indian engineering/technology continues to depend on English terminology for communication just as the technical education continues to be imparted in the medium of English ${ }^{8}$. Even the production of Indian technical literature is in English : English is the major code in the developing multi-coded society of India and terminological growth (whether original or translated) is integral with it. Unless we have some indigenous development of science/technology independent of the Western knowledge, creation of new or special terms in Indian language(s) indicating our technical progress may not be effective. As of today, technical language in Hindi or other Indian languages is hardly produced as original texts; it is largely texts translated from English (rarely, other languages). There is also no worthwhile research activity in the field of mining technology indigenous to India where one needs to find or form terms for new concepts in English. Our technological progress is registered in a borrowed linguistic creation, English, and unless the government enforces use of Hindi or regional languages in University education and changes the medium of instruction, terminological 
studies in Indian languages will not gain the necessary impetus. Politics in language has adversely affected both 'term' and terminology development in the country's national language.

However, a systematic study of terminology is important in the context of education in India both for development of science and technology and writing of engineering and technology textbooks, manuals, and academic papers in Indian languages. The ESP teaching in technical institutions needs to incorporate such aspects of terminology which are useful for ordering of knowledge on bases of the ralationships of concepts, transfer of knowledge, skills and technology, and reading of scientific and technical texts, scientific writing and editing, translating scientific and technical texts into other languages, abstracting and condensing subject information, storing and retrieving technical information, etc. Technical students also need to be aware of the related sociolinguistic factors and use of computer in terminology transfer.

As far as the teaching of ESP at Indian School of Mines is concerned, mining terminology which forms a part of the specific language hardly poses any difficulty to students in understanding or communicating mining engineering. The students are already familiar with the structural patters of English before they do a one- or two-semester skills oriented ESP to communicate effectively in the first year of the 4-year course. The remaining three years that they study mining engineering they simultaneously learn the specialist vocabulary of the subject and it is not reported that they have any difficulty in following/using the specialist terms/words. In the ESL (English as a Second Language) situation that obtains in India they are not separately taught the special terminology before taking the specialised course though the special term is defined, discussed and explained, wherever necessary, by the subject teacher in course of his teaching. Teaching of mining terms in isolation is not envisaged necessary either by students or by teachers ${ }^{9}$.

But as our institution (ISM) is collaborating with mining institutions in Poland, GDR, UK, USA and other countries, both the subject teachers and students are aware of the need for effective translation for oral/written communication. Researchers also face the problem of mis-communication when they are going through publications originating from Germany, Russia or Czechoslovakia, either original or in English translation. As translation invariably involves conceptual transfer of a message from one language to another, they feel the translation of mining literature should be done by mining engineer translators who have not only intimate knowledge of the subject and its terminology with sufficient span of usage of language but also ability to grasp complet and subtale concepts in one language and convey them to another language for 'specific purposes' 10 . They should be familiar with the mechanism for creation and coordination of terms and/or their abbreviations. This expectation makes the role of subject specialists and ESP teachers significant for terminological practices. The future engineers will be linguistically better equipped if they could be sensitized to the linguistic and functional aspects of scientific communication by teaching the terminological principles and their application in specific fields as part of the engineering education at graduate/ postgraduate level.

With the present government's emphasis on "absorption of modern technology" in our school system ${ }^{11}$, we may confidently expect to see several new disciplines with more specialised communication between man/men, man/machine, and machine/machine coming to maturity. Techniques of information storage, classification, retrieval which utilize the powerful tools available in the modern high speed computer, information theory, and various applications of symbolic logic will go a long way to improve scientific/technical communications in a country like India. Additionally, if the government 
encourages the use of Indian languages in higher technical education and adopts a terminological system on international lines to standardize terms and harmonize conflicting usage in specific fields, it will do much to create the desired terminologyconsciousness among teachers, scientific and technical writers/editors, and others who transfer knowledge and language mediators who need terminologies for translation and interpretation. The theoretical and methodological problems, some of which I have only tried to indicate as an ESP teacher, can be minimised if the international dimension of terminology is recognised with a synchronic approach to deliberate language formations, their study and research.

R.K. SINGH

INDIAN SCHOOL OF MINES, DHANBAD

Endnotes and references

1. Comprehension Glossary of Technical Terms, Vol. I (New Delhi, Commission for Scientific and Technical Terminology, Ministry of Education, Government of India, 1973), p. vii.

2. SINGH, R.K. (1982) : "Some Reflecting on Terminology" in The Journal of English Language Teaching (India), Vol. XVII, No 1 (Jan.-Feb.), and its adapted version in Infoterm Newsletter 24, October 18, 1982. Also cf. the quotation in Helmut Felber and Wolfgang Nedobity (1983) : "Terminology Teaching and Training in Countries with less Developed Technical Languages", TermNet News, p. 6.

3. Incidentally, Professor N.L. Sharma happens to be the first person who wrote (in collaboration with two other colleagues) the first textbook in Hindi on a subject of Mineral science, making use of the terminologies published by the Standing Commission for Scientific and Technical Terminology : N.L. Sharma, V.K. Singh, and J.P. Tiwari (1970) : Khanij, Shail Tatha Arthic Bhoovigyan, Allahabad, Saroj Prakashan.

As the other author, j.P. Tiwari tells me, they invariably used more easily understandable terms than the unfamiliar ones given by Raghu Vira and also preferred to give both the English and Hindi equivalents in the text.

4. Engineering Glossary I (1966) : New Delhi, Standing Commission for Scientific and Technical Terminology, Ministry of Education, Government of India, pp. xix-xx.

5. Raghu Vira (1981) : A Comprehensive English-Hindi Dictionary, New Delhi, International Academy of Indian Culture, pp. 49-51.

6. Helmut Felber (1979) : "Theory of Terminology, Terminology Work and Terminology Documentation", Fachsprache 1, Vol. 1-2, p. 21.

7. As Raghu Vira suggests, there are nearly 600 specialist subject fields, and terminologies are available for haif of them in about 60 languages at the moment. "In such a cause", it is relevant to quote Felber, "one will have to follow certain terminographic principles so that the systematic order of concepts in the various languages are comparable." Helmut Felber (1984) : Terminology Manual, Paris, Unesco and Infoterm, pp. 6-7.

8. According to an empirical study reported in Braj B. Kachru (ed.) (1983) : The Other Tongue : English Across Cultures, Oxford, Pergamon Institute of English, pp. 145-149, the majority of students in South India ( 52 percent) think that their job prospects would be excellent if their education was through English. English is considered as a prestige language and it plays a powerful role in the mass media. It is consistantly preferred to the mother tongue and Hindi, for, it is believed, they lack the technical registers used in academic and professional interaction (p. 149).

9. Textbooks like those in the Regents' English for Career series, 1978 (Mining and Metallurgy in English, ed. Eugene J. Hall), or the Macmillan Career English series, 1984, ed. Richard A. Meyers, are designed mainly to teach specific terms of a subject, reducing ISP to the lexical level. This, as Hoffman (1979) also suggests, is not necessary. Cf. quotes in J.H. Picard (1983) : "Terminology in the Service of the Translator", Termnet News, No 7, pp. 42-43.

10. Robin Turner (1980) : "A Note on 'Special Languages' and 'Specific Purposes', Unesco ALSED LSP Newletter, Vol. 1.4, № 1 (November).

11. The Prime Minister, Mr. Rajiv Gandhi's broadcast to the nation, January 5, 1985. 